\title{
Papillary Muscle
}

National Cancer Institute

\section{Source}

National Cancer Institute. Papillary Muscle. NCI Thesaurus. Code C33259.

Any one of the group of small muscles located in the ventricles of the heart that insert onto the ventricular wall and are continuous at the opposite end with the chordae tendineae, which insert onto the free edge of the atrioventricular valves, functioning to keep the valves closed during ventricular systole. 